\title{
Improving bone mineral density reporting to patients with an illustration of personal fracture risk
}

Stephanie W Edmonds ${ }^{1,2^{*}}$, Peter Cram ${ }^{3,4}$, Xin Lu , Douglas W Roblin ${ }^{5,6}$, Nicole C Wright ${ }^{7}$, Kenneth G Saag ${ }^{8}$, Samantha $\mathrm{L}$ Solimeo ${ }^{9}$ and on Behalf of the PAADRN Investigators

\begin{abstract}
Background: To determine patients' preferences for, and understanding of, FRAX ${ }^{\circledR}$ fracture risk conveyed through illustrations.

Methods: Drawing on examples from published studies, four illustrations of fracture risk were designed and tested for patient preference, ease of understanding, and perceived risk. We enrolled a convenience sample of adults aged 50 and older at two medical clinics located in the Midwestern and Southern United States. In-person structured interviews were conducted to elicit patient ranking of preference, ease of understanding, and perceived risk for each illustration.
\end{abstract}

Results: Most subjects ( $n=142)$ were female (64\%), Caucasian (76\%) and college educated (78\%). Of the four risk depictions, a plurality of participants (37\%) listed a bar graph as most preferred. Subjects felt this illustration used the stoplight color system to display risk levels well and was the most "clear," "clean," and "easy to read". The majority of subjects (52\%) rated the pictogram as the most difficult to understand as this format does not allow people to quickly ascertain their individual risk category.

Conclusions: Communicating risk to patients with illustrations can be done effectively with clearly designed illustrations responsive to patient preference.

Trial Registration: ClinicalTrials.gov Identifier: NCT01507662

Keywords: Osteoporosis, DXA Scan, Risk, Fracture, Bone, Patient education

\section{Background}

Osteoporosis [OP] is a common disease of the skeletal system associated with fragility fractures. OP fractures, particularly of the hip, have been associated with increased morbidity and mortality, and decreased quality of life [1]. Because of these factors and the increased likelihood of chronic pain and dependence, persons with or who are at risk of developing OP will likely want to know their risk of having a fracture. Health care providers can quickly calculate an individual patient's 10year probability of hip and other major osteoporotic

\footnotetext{
* Correspondence: stephanie-edmonds@uiowa.edu

'Division of General Medicine, University of lowa Carver College of Medicine, lowa City, IA, USA

${ }^{2}$ College of Nursing, University of lowa, lowa City, IA, USA

Full list of author information is available at the end of the article
}

fractures combined (hip, vertebrae, distal forearm and proximal humerus) by using the World Health Organization's FRAX ${ }^{\oplus}$ fracture risk assessment tool (www.shef. ac.uk/FRAX/) [2]. This web-based calculator uses 11 factors (age, race, sex, body mass index, prior history of fracture, parental history of fracture, secondary diseases, steroid use, smoking and alcohol intake, and bone mineral density [BMD] as determined by a dual energy Xray absorptiometry [DXA]) to calculate an individual's personalized 10-year absolute fracture risk. Providers typically use this risk calculation to communicate with patients when considering initiation of medication therapy and lifestyle counseling in the areas of nutrition, exercise, and tobacco and alcohol use. Because OP is asymptomatic and DXA alone is insufficient to predict fracture risk, providing individualized risk is an 
important strategy for reducing fracture risk and related morbidity. Unfortunately, it is unclear whether patients understand their DXA results, are able to act on this vital information in an appropriate way, or that health care providers know how to convey DXA results and FRAX $^{\circledast}$ in a way that patients understand [3-7].

According to the Health Belief Model [HBM], prevention and adherence behaviors rely on patients knowing and understanding that they are at risk for a disease [8]. The HBM theorizes that patients will take necessary actions if they believe they are at risk for poor outcomes and that these poor outcomes can be prevented (e.g., osteoporotic fractures) by taking a recommended action (e.g., pharmacotherapy, calcium, weight-bearing exercises). In other words, patients may choose not to employ fracture risk reduction behaviors if they do not believe they are at risk, if they are not prepared to take action, or if they do not perceive benefits from the action. Accordingly, the OP prevention literature has demonstrated that patients at risk for fractures do not take actions to reduce their risks in part because they do not recognize their at-risk status [4,7,9-17].

The communication of risk is more complex than simply providing patients with information about their condition, its treatment, and sequelae. Health care providers seeking to communicate risk to patients must take into account their patients' health and numeracy skills. Numeracy is the ability one has understanding risk concepts and basic probability [18,19]. As is the case for literacy [20], average numeracy in the United States is low [21]. Even highly educated samples perform poorly on fairly simple probability questions [18]. The consequences of poor numeracy for health behavior are high in the case of OP. For example, a $20 \%$ chance of major osteoporotic fracture in 10 years represents a high risk of sustaining a fracture, but patients may not understand that $20 \%$ is a high risk when receiving this number verbally or in a letter from their doctor [22].

Combining written, numeric, and illustrated representations of risk can ameliorate the effects of lower numeracy on patient understanding [23-26]. Studies to maximize patient comprehension of risk have employed a variety of images including bar graphs, pie charts, "thermometers," and icon arrays. However, none of these studies have shown a single approach to be the most preferred or comprehensible to patients. In a study on comprehension of breast cancer risk, patients preferred an icon array to a bar graph [25]. Ghosh et al. found that combining a bar graph with an icon array lead to better understanding for patients who inaccurately perceived themselves to initially be at high risk of breast cancer [26]. Hill et al. found when presented with absolute risk of heart attack in the next five years, most patients preferred a risk thermometer [24]. Despite these promising directions, the published literature clearly lacks consensus on which depiction patients most easily understand, prefer, and are most motivated by $[27,28]$. In the field of $\mathrm{OP}$, we were able to identify only a single trial that evaluated the use a pictogram to display fracture risk. The pictogram displayed personal risk of fracture and absolute risk reduction with pharmacotherapy and was used in a decision aid to help patients understand the relative benefits of taking bisphosphonates. Patients who used the decision aid were twice as likely to correctly identify their 10-year fracture risk as patients who did not see the pictogram [29].

We studied the feasibility of developing an instrument combining text and illustration to convey fracture risk to patients in a way that they prefer and understand. We set out to test patients' preferences for, ease of understanding, and perceived fracture susceptibility after presenting subjects with a series of alternative illustrations depicting individualized risk of major fracture derived from a FRAX ${ }^{\odot}$ score. Our objectives were to identify: which depictions patients prefer and why; whether patients can correctly ascertain fracture risk from the images and not over or underestimate risk; and which depiction is most associated with the desired health behavior outcome of seeking follow-up care from the referring provider. This study informed the instrument development for our current randomized clinical trial, The Patient Activation After DXA Result Notification (PAADRN) study, which tests the efficacy of a direct-toconsumer mailed DXA reporting intervention to activate patients for appropriate follow up with their health care providers based on test results [30].

\section{Methods}

\section{Illustration development}

Our team of health care practitioners, health literacy, and health communication experts developed depictions of FRAX ${ }^{\oplus}$ results. First, we reviewed published decisionmaking and risk communication literature to gain insight into which types of depictions had been shown to be effective at visually communicating risk $[24,26]$. Next, we created illustrations relevant to OP and FRAX ${ }^{\oplus}$. The FRAX $^{\circledast}$ calculation tool provides two scores: hip fracture risk and major osteoporotic (hip, shoulder, clinical spine, or forearm) fracture risk. We selected major osteoporotic fracture for this study because it addresses all bones and provides the highest percent risk of the two calculations, which may have more of an impact on a general population with low health numeracy. Risk categories of "normal", "moderate", and "high" risk for fracture were layered onto these illustrations. These categories were determined using treatment guidelines from National Osteoporosis Foundation, where a risk $\geq 20 \%$ is considered "high" risk for fracture [31]. 
We initially developed three illustrations, FACES, ARROW, and BAR, with each illustration depicting identical $\mathrm{FRAX}^{\oplus}$ results (i.e., a 10-year fracture risk of $21 \%$ ) to conduct face validity evaluation. FACES (Figure 1) is a pictogram comprised of 100 faces. In our example, 79 were smiling and 21 were colored red and frowning, depicting a $21 \%$ risk. ARROW (Figure 2) is informed by the work of Hill, et al [24], and is a horizontally oriented arrow-shaped, directional graph that integrates a red, yellow, and green colored "stoplight" system to indicate risk: Low risk is associated with green, moderate is associated with yellow, and high risk is associated with red shading of equal widths. The BAR illustration (Figure 3), is informed by the work of Price et al., and employed a graduated stoplight color system, but is oriented vertically, similar to thermometer tools [32].

Preliminary validity testing of these initial three illustrations was conducted with clinicians, health communication experts and a convenience sample of our target audience. Some members of our target audience disliked ARROW's truncated scale so a fourth design, STOPLIGHT (Figure 4), was developed. As the name implies, the STOPLIGHT illustration integrates stoplight colors, but unlike the ARROW, STOPLIGHT is a rectangular depiction that does not imply progression and is scaled to $100 \%$ risk.

\section{Participants}

For the more formal assessment, we recruited participants who were similar to our target audience for the PAADRN trial: English-speakers who were 50 years of age and older who had no visual or mental hearing impairments. We obtained our convenience sample $(n=142)$ from clinic reception and waiting areas at two sites, a large teaching hospital in the Midwestern United States (Site A) and a private clinic located in the southeastern part of the country (Site B). These two sites offer significant diversity in terms of geographic location and socioeconomic status of patients served (Site A is a rural safety net hospital while Site B serves primarily privately insured younger patients). We recruited participants by approaching them inperson (Site A) or by posting flyers in the clinic (Site B).
Interviewers attempted to recruit a diverse sample of participants by approaching adults of varying ages, genders, and races and from a variety of clinic settings at each site. This study was approved by the Human Subjects Office at the University of Iowa and the Kaiser Permanente Georgia Institutional Review Board and due to the low anticipated risk to subjects, a waiver of written informed consent was granted.

\section{Study design and measures}

We tested the four illustrations for preference, comprehension and perceived susceptibility using a combination of qualitative and quantitative measures. Participant preferences, comprehension, and perceived susceptibility were assessed using a structured interview. We explained the study to subjects in this way: "Some people need to have a test called a DXA done to figure out how strong their bones are. After the test is done the results are sent to their doctor. In addition to this we want to send the test results directly to patients in a letter that will be easy for them to understand. ... Now I am going to ask you to look at 4 different pictures. We would like to include a picture to help people better understand this risk of breaking a bone". Subjects were shown identical DXA results and associated fracture risk (21\% or high risk) using the four illustrations discussed above. To control for potential confounding associated with priming participants, we presented the illustrations in a random order.

For each depiction, we asked participants a series of paired questions to obtain their ranked preference, ease of understanding, perceived susceptibility and underlying rationale for these perceptions. See Table 1 for examples of the paired items. We used items from the Subjective Numeracy Scale to obtain an independent measure of numeric comprehension [33] and three health literacy screening questions to measure literacy level [34]. At the end of the interview, subjects provided information regarding their history of DXA, osteoporosis status, fracture, and demographic data such as their sex, year of birth, educational attainment, race, and employment status. Participants who completed the 30 minute interview

\begin{tabular}{|lll} 
YOUR risk of breaking a \\
bone in your spine, forearm, \\
shoulder or hip in the next \\
10 years is about $21 \%$. \\
OR \\
$\begin{array}{c}21 \text { out of } 100 \text { will break a } \\
\text { bone, } 79 \text { will not. }\end{array}$
\end{tabular}




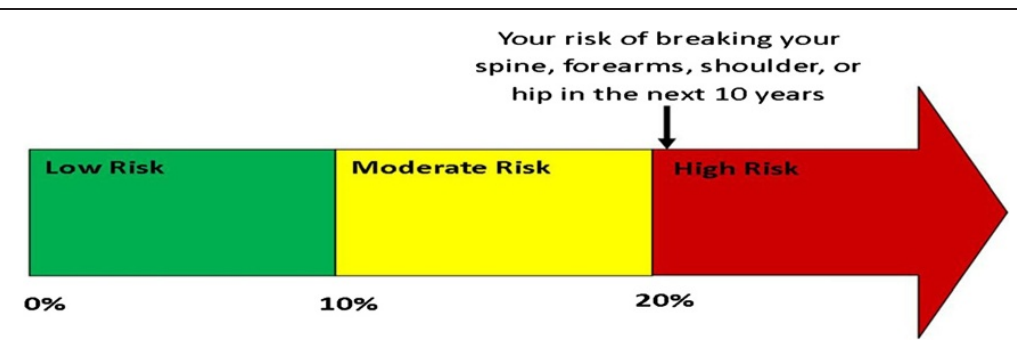

Figure 2 Arrow.

received a voucher for complimentary parking or a gift card to compensate them for their time.

\section{Analyses}

We used a sequential mixed methods approach to gain an in-depth understanding of participants' stated preferences, ease of understanding and their underlying rationale [35]. Quantitative analyses were prioritized and analyzed first to guide the focus of qualitative inquiry. Interview data were entered into a preformatted text

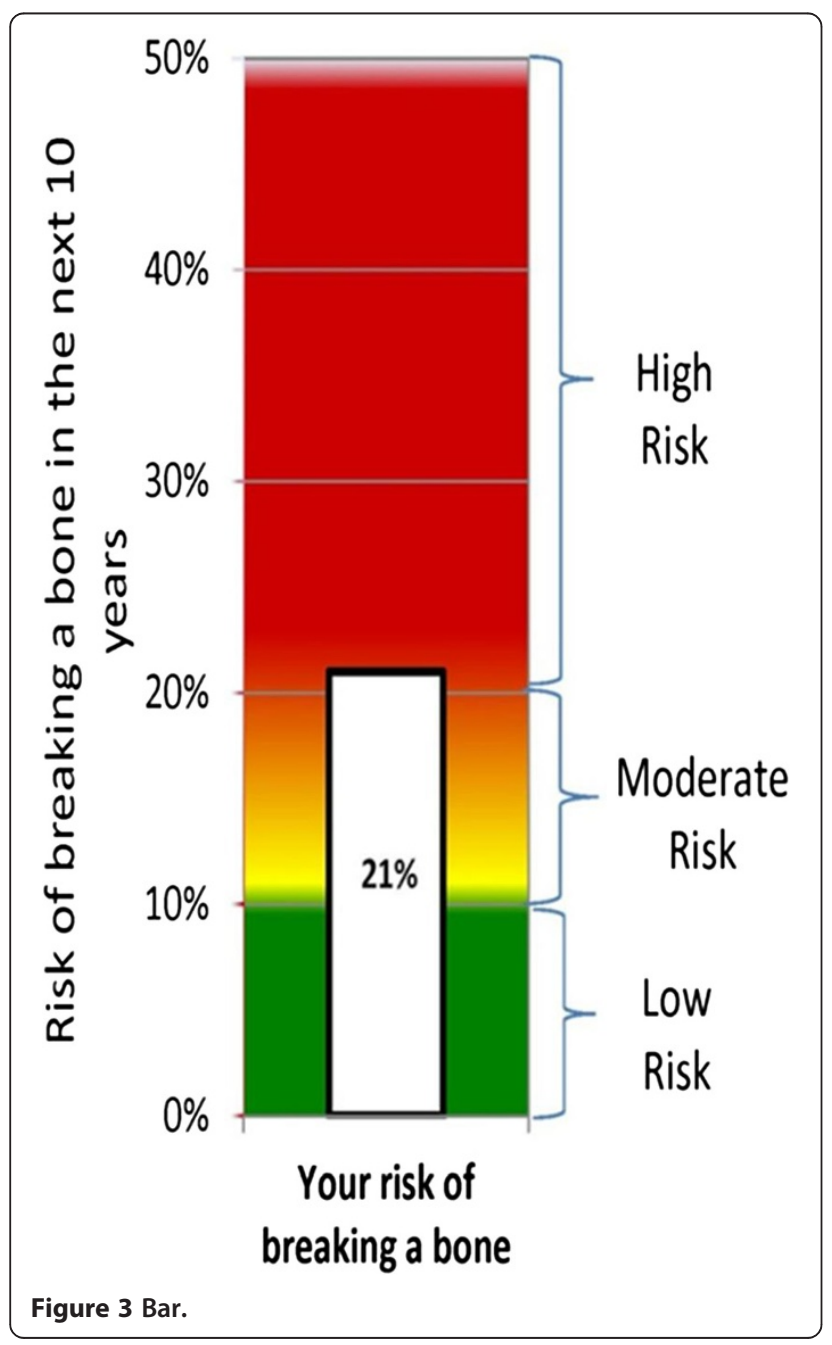

document and imported using preprocessor functions of a qualitative data analysis software platform, MAXQDA (Version 10, 2011). Preprocessing automatically links interview items with subject response and facilitates subsequent linkage of qualitative and quantitative analyses. The close ended, quantitative variables were then exported from the qualitative platform into SAS (Version 9.2 Cary, $\mathrm{NC)}$ for statistical analysis.

\section{Quantitative analysis}

We compared demographic (e.g., age, race, sex) and clinical characteristics (e.g., history of prior DXA scans, history of osteoporosis or prior fracture) of subjects from the two sites. We used two-sampled t-test for comparisons of continuous variables and the chi-squared test for categorical variables. To evaluate how participants ranked preference for the illustration, we first assigned number 1 to the illustration that was most preferred to 4 for the illustration that was least preferred. Then we used Friedman's test to compare the ranks of the most favorite to the least favorite among the four illustrations. Next, we examined differences in ranking between each pair of illustrations by running separate Wilcoxon signed-rank tests and applied Bonferroni correction on the test results. Alternatively, we used Cochran-MantelHaenszel statistics to assess whether the most preferred depictions differed among selected subgroups (e.g., men versus women, more versus less educated).

To examine the comprehension and perceived susceptibility of each picture, we first defined perception of risk by an answer to the question "What would you say is the risk or chance of this person breaking a bone in the next 10 years?" An answer of "High" risk was "correct", other answers (e.g., "Very Low, "Low', "Moderate", "Very High") were "incorrect". We deemed an answer of "High" as correct based on treatment guidelines from National Osteoporosis Foundation, where a risk $\geq 20 \%$ is considered "high" risk for fracture [31]. After that we compared the pictures' ability to convey "correct" risk to subjects using logistic regression. We adjusted for average numeracy and accounted for the within-subject variance by treating subjects as random effect. Alpha level of 0.05 is considered statistically significant. 


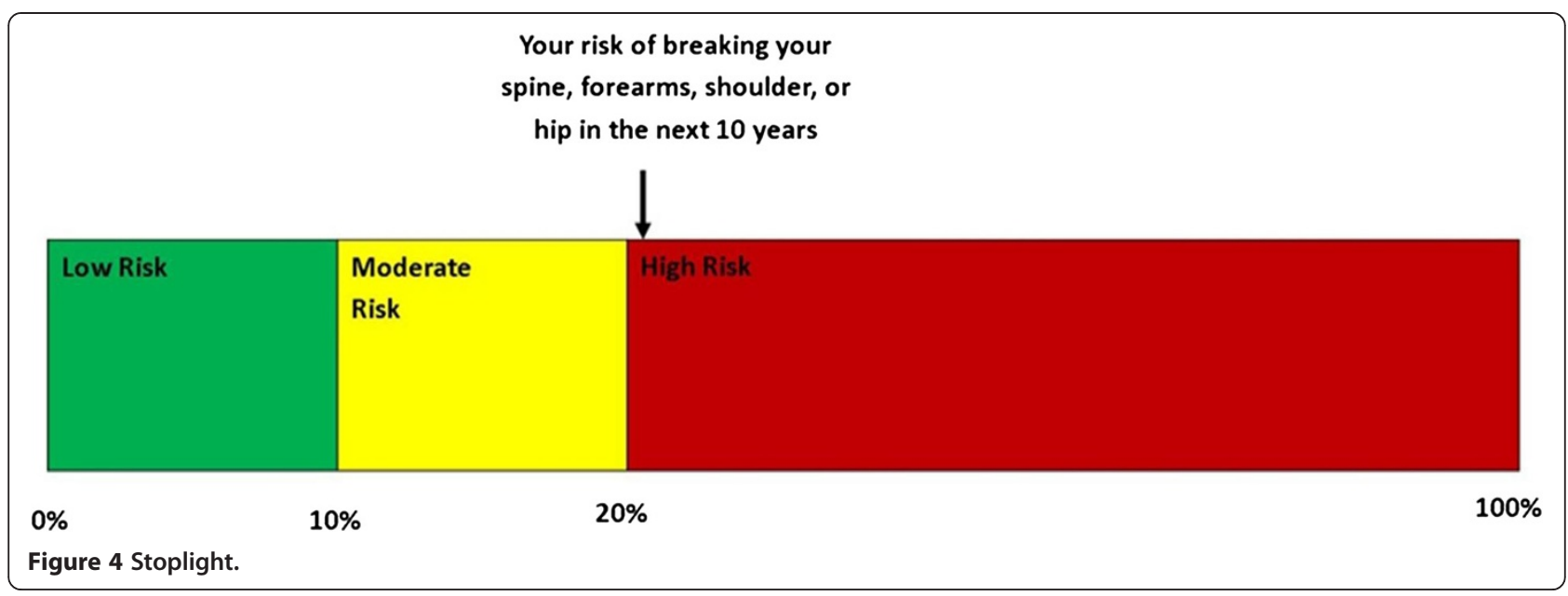

\section{Qualitative analysis}

Two mechanisms were employed to maintain internal validity and reliability of the qualitative data analyses. First, while we employed a sequential mixed methods framework, initial coding of the open ended interview items was conducted concurrently and independently of quantitative analyses. This protected the qualitative investigators from inadvertently "discovering" the quantitative trends. Secondly, the qualitative investigators independently coded the open-ended interview items using a multi-coder team. In sum, data were imported into the qualitative software, automatically coded by topic using the preprocessor function of the program, and then subsequently coded for content by the lead qualitative coder. After the initial coding processes had been performed, the quantitative data were exported for analysis and the qualitative data team worked as a group to review and categorize subject rationales into themes. The themes were reviewed for face validity by the group and the data recoded by the team using the new codebook. Once the quantitative analyses had been finalized, the qualitative team reviewed data pertaining to perceived ease of understanding, preference, dislike, and areas for improvement in order to contextualize and understand the ranking results.

Table 1 Interview Schedule

\begin{tabular}{|c|c|c|c|c|c|}
\hline & \multicolumn{2}{|l|}{ Mode of questioning } & \multicolumn{3}{|c|}{ Construct assessing } \\
\hline & Close-ended (Quantitative) questions & $\begin{array}{l}\text { Open-Ended } \\
\text { (Qualitative) } \\
\text { questions }\end{array}$ & Preference & Comprehension & $\begin{array}{l}\text { Perceived } \\
\text { susceptibility }\end{array}$ \\
\hline \multirow{5}{*}{$\begin{array}{l}\text { For each figure individually, } \\
\text { presented to participants } \\
\text { in random order }\end{array}$} & & $\begin{array}{l}\text { What is this picture } \\
\text { trying to show you? }\end{array}$ & & $\checkmark$ & \\
\hline & $\begin{array}{l}\text { What would you say is the risk or chance of } \\
\text { this person breaking a bone in the next } 10 \\
\text { years? }\end{array}$ & & & $\checkmark$ & $\checkmark$ \\
\hline & (Very high, High, Moderate, Low, Very Low) & & & & \\
\hline & & $\begin{array}{l}\text { What do you like } \\
\text { about this picture? } \\
\text { Why? }\end{array}$ & $\checkmark$ & & \\
\hline & & $\begin{array}{l}\text { What do you not } \\
\text { like about this } \\
\text { picture? }\end{array}$ & $\checkmark$ & & \\
\hline \multirow[t]{4}{*}{$\begin{array}{l}\text { For all figures, in } \\
\text { comparison to one another }\end{array}$} & $\begin{array}{l}\text { Rank the pictures from your most favorite to } \\
\text { your least favorite explain your decision. }\end{array}$ & $\begin{array}{l}\text { Explain your } \\
\text { decision. }\end{array}$ & $\checkmark$ & & \\
\hline & $\begin{array}{l}\text { Which picture was easiest for you to } \\
\text { understand? }\end{array}$ & Why? & & $\checkmark$ & \\
\hline & $\begin{array}{l}\text { Which picture was hardest for you to } \\
\text { understand? }\end{array}$ & $\begin{array}{l}\text { What could we do } \\
\text { to make it better? }\end{array}$ & & $\checkmark$ & \\
\hline & $\begin{array}{l}\text { If these pictures showed YOUR risk, which one } \\
\text { would make you most worried about breaking } \\
\text { a bone? }\end{array}$ & & & & $\checkmark$ \\
\hline
\end{tabular}




\section{Results}

\section{Characteristics of participants}

We interviewed 142 participants, a majority of whom were female (64\%) and Caucasian (76\%) (Table 2). Demographic characteristics differed between the two sites. Overall, Site B had a larger proportion of female (p-value $=0.03$ ), African American ( $\mathrm{p}$-value $<0.001$ ), and highly educated (p-value $<0.01$ ) participants than Site A. Across sites more than half of subjects reported their health being "very good" or "excellent" (55\%).

\section{Preference}

When we examined participants' ranking, there was a statistically significant difference in preference among the four illustrations $(P<0.001)$. Median interquartile range (IQR) of the ranks for ARROW, BAR, FACES and STOPLIGHT were 3 (2 to 3 ), 2 (1 to 3 ), 4 ( 2 to 4 ) and 2

Table 2 Characteristics of the study sample $(n=142)$

\begin{tabular}{llll}
\hline Characteristics & All & Site A & Site B \\
& sites & Sample & Sample \\
& $56 \%$ & $44 \%$ \\
& & &
\end{tabular}

\begin{tabular}{|c|c|c|c|c|}
\hline \multicolumn{5}{|l|}{ Gender, \% } \\
\hline Female & 64 & 56 & 74 & ${ }^{*} 0.03$ \\
\hline \multicolumn{5}{|l|}{ Age, \% } \\
\hline $50-59$ & 35 & 29 & 44 & \\
\hline $60-69$ & 39 & 41 & 36 & \\
\hline $70+$ & 26 & 30 & 21 & \\
\hline \multicolumn{5}{|l|}{ Education, \% } \\
\hline High school or less & 22 & 30 & 13 & ${ }^{*} 0.002$ \\
\hline Some college & 34 & 38 & 30 & \\
\hline College gaduate or more & 44 & 32 & 57 & \\
\hline \multicolumn{5}{|l|}{ Race,\% } \\
\hline White & 76 & 93 & 55 & ${ }^{*}<0.001$ \\
\hline Black & 19 & 4 & 39 & \\
\hline Other & 5 & 4 & 7 & \\
\hline $\begin{array}{l}\text { Literacy, Mean (SD) Range 1-5 with } \\
\text { higher number better literacy }\end{array}$ & $3.3(0.6)$ & $3.4(0.6)$ & $3.2(0.5)$ & \\
\hline $\begin{array}{l}\text { Numeracy, Mean (SD) Range 1-6 with } \\
\text { higher number better numeracy }\end{array}$ & $3.5(1.4)$ & $4.3(1.2)$ & $2.5(0.9)$ & ${ }^{*}<0.001$ \\
\hline \multicolumn{5}{|l|}{ General health, \% } \\
\hline Excellent & 14 & 13 & 15 & \\
\hline Very good & 41 & 46 & 36 & \\
\hline Good & 37 & 34 & 40 & \\
\hline Fair & 8 & 7 & 8 & \\
\hline Poor & 1 & 0 & 2 & \\
\hline \multicolumn{5}{|l|}{ Bone health, \% } \\
\hline History of previous DXA & 46 & 38 & 55 & \\
\hline $\begin{array}{l}\text { History of osteoporosis or } \\
\text { osteopenia }\end{array}$ & 24 & 19 & 31 & \\
\hline Fracture history & 16 & 13 & 19 & \\
\hline
\end{tabular}

Note: *indicates variables for which the sites are significantly different $(p<.05)$.
(2 to 3), respectively. Bonferroni correction yielded a significance level set at $\mathrm{p}<0.008$. There were no significant differences between ARROW and BAR $(\mathrm{p}=0.03)$, ARROW and STOPLIGHT $(\mathrm{p}=0.01)$, ARROW and FACES $(\mathrm{p}=$ $0.02)$, BAR and STOPLIGHT $(\mathrm{p}=0.82)$. However, the overall ranking for FACES was significantly worse than BAR $(\mathrm{p}<0.001)$ and STOPLIGHT $(\mathrm{p}<0.001)$. Although ARROW, BAR, and STOPLIGHT appeared to be statistically similar, we chose BAR to be the winning illustration based on its median (IQR) statistic.

When we assessed the depiction that was ranked most preferred, a significantly higher proportion of respondents chose BAR as their most preferred illustration (selected by $37 \%$ ) as compared to STOPLIGHT (selected by $24 \%$ ), FACES (selected by $22 \%$ ), or ARROW (selected by $17 \%)(\mathrm{p}<0.05)$, though FACES was ranked the least favorite by 65 subjects $(52 \%)$. This coincided well with the findings using the entire ranking information. The participants ranked BAR as the most preferred by all age groups $(33 \%, 31 \%, 39 \%)$, females $(33 \%)$, males $(36 \%)$, those that attended college $(45 \%, 32 \%)$ and Whites (35\%). FACES was ranked most preferred by two subgroups; non-Whites (Blacks $44 \%$ and other $40 \%$ ) and those that did not attend college (34\%). However, there were no significant differences for illustration preference among subgroups by age, race, sex, site, education attainment, or average numeracy Table 3.

The primary reasons why respondents selected BAR as their favorite included the association of red color with the risk presented and the categorization of risk (low, moderate, and high) in association with the numeric value of reported risk. These positive appraisals are reflected in the following subject responses:

"The color shows me I'm in high risk, without the color I would assume $21 \%$ is low".

"I like how [BAR] is broken out with the colors and then that is reiterated with the scales of low, moderate, and high. And you got your percentages. And the colors really drive that all home".

"[BAR] shows percentages of low, middle, high well and is easy to understand".

Research assistants then asked subjects why they ranked the other illustrations lower. One reason given was that the increasing risk implied by ARROW and that STOPLIGHT made it difficult to identify where one stood in regard to the overall risk represented by STOPLIGHT. FACES was reported least preferred because of its lack of clearly defined risk groups, the perceived "childlike" and "unprofessional" feel of FACES, 
Table 3 Subjects' preference for illustration format

\begin{tabular}{|c|c|c|c|c|c|c|}
\hline & \multicolumn{4}{|c|}{ Favorite illustration (percentage who picked as their most preferred) } & \multirow[b]{2}{*}{ No. missing } & \multirow[b]{2}{*}{ P-valu } \\
\hline & Arrow & Bar & Faces & Stoplight & & \\
\hline Total $(n=127)$ & 17 & 37 & 22 & 24 & 15 & 0.01 \\
\hline \multicolumn{7}{|l|}{ Gender, \% } \\
\hline Female $(\mathrm{n}=81)$ & 20 & 35 & 25 & 21 & \multirow[t]{2}{*}{15} & \\
\hline Male $(n=46)$ & 13 & 41 & 17 & 28 & & \\
\hline \multicolumn{7}{|l|}{ Education, \% } \\
\hline High school or less $(n=27)$ & 11 & 22 & 30 & 37 & \multirow[t]{3}{*}{19} & \\
\hline Some college $(n=43)$ & 21 & 47 & 12 & 21 & & \\
\hline College graduate or more $(n=53)$ & 17 & 38 & 25 & 21 & & \\
\hline \multicolumn{7}{|l|}{ Age, \% } \\
\hline $50-59(n=49)$ & 18 & 37 & 18 & 27 & \multirow[t]{3}{*}{15} & \\
\hline $60-69(n=48)$ & 21 & 33 & 21 & 25 & & \\
\hline $70+(n=30)$ & 10 & 43 & 30 & 17 & & \\
\hline \multicolumn{7}{|l|}{ Site, $\%$} \\
\hline Site $A(n=66)$ & 18 & 38 & 15 & 29 & & \\
\hline Site $B(n=61)$ & 16 & 36 & 30 & 18 & 15 & \\
\hline \multicolumn{7}{|l|}{ Race, \% } \\
\hline White $(n=94)$ & 18 & 38 & 17 & 27 & \multirow[t]{3}{*}{16} & \\
\hline Black $(n=27)$ & 19 & 33 & 37 & 11 & & \\
\hline Other $(n=5)$ & 0 & 20 & 40 & 40 & & \\
\hline
\end{tabular}

and the disconnect between the risk reported and the perceived risk, as evidenced in these comments:

"[FACES] doesn't tell you what risk group you are in".

"I feel like a three year old. And it makes me feel like my percentage isn't high".

"[FACES]: It is too confusing and too much going on. You want to see the numbers and not have to count them up".

\section{Ease of understanding, comprehension and perceived susceptibility}

As expected, the illustrations participants preferred were also the ones reported as most easily understood. More subjects listed BAR (34\%) than the other three illustrations. STOPLIGHT and ARROW were ranked second, listed as easiest to understand by $19 \%$ of participants. Participant characteristics were not significantly associated with reported difficulty in understanding at the 0.05 level of significance Table 4 .

When asked why they selected a particular depiction as easiest to understand, participants listed stoplight color associations, the relationship of individual risk to the risk groups, and overall formatting as reasons. The stoplight color offset of the individual risk from the bar graph in BAR was noted as helpful, as this participant explained, "The ways they did the ranking and highlighted the different areas. It also puts your test score in with the white so you can actually see the scale". As for why other formats were perceived as more difficult to comprehend, subjects commented:

"Counting all the little [FACES] and you don't get a scale".

"[FACES] Gives no feeling of where I stand as far as my risk".

"[STOPLIGHT] It seems like there is nothing on the left side in the low risk, and you don't have far to go to high risk".

"When you look at [ARROW] and realize it's not $100 \%$, it's deceptive".

In order to maximize the potential activation impact of the final illustration, for each depiction participants were asked "What is this picture trying to show you?", "What would you say is the risk or chance of this person breaking a bone in the next 10 years?", and "Which picture would make you feel the most worried?" Across all 
Table 4 Subjects' opinion on comprehension of illustration formats

\begin{tabular}{|c|c|c|c|c|c|c|}
\hline & \multicolumn{4}{|c|}{ Easy to understand picture (percentage who picked as the easiest to understand) } & \multirow[b]{2}{*}{ No. missing } & \multirow[b]{2}{*}{ P-value } \\
\hline & Arrow & Bar & Faces & Stoplight & & \\
\hline Total $(n=124)$ & 19 & 34 & 27 & 19 & 18 & 0.06 \\
\hline \multicolumn{7}{|l|}{ Gender, \% } \\
\hline Female $(n=79)$ & 22 & 33 & 32 & 14 & \multirow[t]{2}{*}{18} & \\
\hline Male $(n=45)$ & 16 & 36 & 20 & 29 & & \\
\hline \multicolumn{7}{|l|}{ Education, \% } \\
\hline High school or less $(n=26)$ & 19 & 19 & 35 & 27 & \multirow[t]{3}{*}{21} & \\
\hline Some college $(n=42)$ & 17 & 45 & 21 & 17 & & \\
\hline College graduate or more $(n=53)$ & 21 & 32 & 28 & 19 & & \\
\hline \multicolumn{7}{|l|}{ Age, $\%$} \\
\hline $50-59(n=48)$ & 23 & 22 & 21 & 23 & \multirow[t]{3}{*}{18} & \\
\hline $60-69(n=48)$ & 19 & 31 & 31 & 19 & & \\
\hline $70+(n=28)$ & 14 & 39 & 32 & 14 & & \\
\hline \multicolumn{7}{|l|}{ Site, \% } \\
\hline Site $A(n=62)$ & 23 & 32 & 21 & 24 & \multirow[t]{2}{*}{18} & \\
\hline Site $B(n=62)$ & 16 & 36 & 34 & 15 & & \\
\hline \multicolumn{7}{|l|}{ Race, \% } \\
\hline White $(n=91)$ & 20 & 35 & 22 & 23 & \multirow[t]{3}{*}{19} & \\
\hline Black $(n=27)$ & 19 & 30 & 44 & 7 & & \\
\hline Other $(n=5)$ & 20 & 20 & 40 & 20 & & \\
\hline
\end{tabular}

illustrations, participants identified nine key messages. See Table 5. Participants' comments about 10-year fracture risk were evenly represented among the illustrations, but comments about STOPLIGHT and ARROW more frequently mentioned that the image communicated "high risk". In response to correctly matching the

Table 5 Key risk messages identified by respondents

\begin{tabular}{|c|c|}
\hline $\begin{array}{l}\text { Risk message } \\
\text { category }\end{array}$ & Associated responses \\
\hline Fracture risk & $\begin{array}{l}\text { "Risk of breaking a bone in spine, forearms, } \\
\text { shoulders, or hip". }\end{array}$ \\
\hline High risk & "I'm in the high risk". \\
\hline $\begin{array}{l}\text { Ten-year fracture } \\
\text { risk }\end{array}$ & $\begin{array}{l}\text { "In the next } 10 \text { years I am at a high risk for } \\
\text { breaking those bones". }\end{array}$ \\
\hline General health risk & $\begin{array}{l}\text { "Showing you from the high to low of risk } \\
\text { involved". }\end{array}$ \\
\hline $\begin{array}{l}\text { Personal fracture } \\
\text { risk }\end{array}$ & $\begin{array}{l}\text { "It is telling me where my bone density lies, } \\
\text { and the risk of it". }\end{array}$ \\
\hline Preventable risk & $\begin{array}{l}\text { "That you have } 10 \text { years to get your act together } \\
\text { or you'll be in the red". }\end{array}$ \\
\hline Action is required & $\begin{array}{l}\text { "If you are in the red part you best be getting } \\
\text { to the doctor". }\end{array}$ \\
\hline Bone density results & $\begin{array}{l}\text { "Percent of risk of osteoporosis in spine, forearms, } \\
\text { shoulder, or hip in the next } 10 \text { years". }\end{array}$ \\
\hline Risk categories & $\begin{array}{l}\text { "It's showing you are at moderate risk. High risk is } \\
\text { clear up here. And it's a little more than low risk". }\end{array}$ \\
\hline
\end{tabular}

depiction to high risk, ARROW and STOPLIGHT had the highest correct risk perception ( $72 \%$ and $62 \%$ of responses, respectively). Different pictures were associated with recognizing the "correct" risk ( $\mathrm{p}$-value $=0.002$ ). ARROW and STOPLIGHT had similar capacity to convey the risk correctly (odds ratio $=1.5,95 \% \mathrm{CI}=(0.9-2.6), \mathrm{p}=$ 0.15 ) and were significantly better than BAR and FACE. For example, ARROW was 3.2 times better in rendering "correct" perception of risk comparing to BAR (95\% CI = (1.9-5.5), p <0.001), and 37 times better than FACE $(95 \%$ $\mathrm{CI}=(16.3,84.9), \mathrm{p}<0.001)$. Compared to STOPLIGHT, BAR is 4 times likely to represent "under" risk". Compared to STOPLIGHT, FACES is 30 times likely to represent "under" risk. Most participants (75\%) responded that FACES depicted a person with low risk of fracture, while $23 \%$ thought STOPLIGHT showed a very high risk. Lastly, a majority of participants thought BAR showed a moderate risk of fracture (58\%). Average numeracy was not associated with recognizing the "correct" risk ( $\mathrm{p}=0.63)$.

Finally, participants rated STOPLIGHT AND ARROW as the most worrisome illustrations (33\% and 34\%, $\mathrm{p}<0.001)$. When asked why these illustrations instilled concern, typical responses included, "It [ARROW] points like it is going to get worse" and "[STOPLIGHT] would alarm you more because more length to the high risk and less to the moderate". 


\section{Discussion}

In this mixed methods study, we found that participants preferred the BAR illustration and they did not prefer the icon array FACES. The use of stoplight colors to reflect fracture risk category was popular. We presented participants with four illustrations of identical risk in random order, asked them to rate their preference, ease of understanding, intent, and worrisome nature, and then asked them to explain their ratings. We found differences in participants' response to the illustrations, demonstrating that the representation of risk has important bearing on patient's consideration of health care information.

There was no strong consensus on the preferred illustration as none was preferred by more than half of participants. The BAR was most preferred of the four with $37 \%$ selecting it as their favorite option. Additionally, respondents listed BAR as the easiest to understand illustration. Our findings were similar to the findings of other studies that used a vertical bar graph to display risk [36,37]. McCaffery et al. found that participants had a strong preference for a bar graph versus an icon array, such as our FACES design. Additionally, they found that participants were more likely to accurately identify risks of $>10 \%$ using a bar graph when compared to an icon array [36]. Hawley et al. also found that participants performed better on verbatim tasks (the ability to correctly read numbers from graphs) when shown a bar graph versus an icon array [38]. While participants reported that BAR was the easiest to understand of the four illustrations, they did not perform as well when asked about risk severity. Due to the participant feedback, we felt that the color gradation caused this confusion and not the bar-type format.

Risk communication studies are increasingly employing icon arrays as a mechanism for addressing low numeracy among patients. However icons arrays were least likely to lead to a correct identification of risk category by participants. Participants were least likely to prefer the icon array FACES. The FACES option likely suffered from a lack of risk stratification from low to moderate and then to high risks, a design feature in the other types of graphics that was very much preferred by participants. Our data suggest that patients with lower educational attainment may be more likely to prefer icon arrays to other illustrations; however, the difference between educational subgroups was not statistically significant. Additionally, we found that preference for a depiction was not significantly associated with average numeracy levels. Our finding that icon arrays are least preferred by some respondents may be in part due to the arrangement of negative icons within the array. There is evidence to suggest that random arrangement of icons within the array more effectively produces increased susceptibility [39], however open-ended comments by our respondents revealed that they found the depiction of a happy or sad face to be infantile, so it is unclear whether random arrangement would have surmounted that appraisal.

Use of stoplight colors emerged as a clear factor in respondents' preferences and interpretation of information. The universal stoplight coloring system which equates the color green with health and positive movement, yellow with caution and slowed movement, and red with danger, was clearly internalized and applied to the interpretation of risk. Similar uses of the traffic light color system were used in other studies and found to be well perceived by participants in conveying risk [24,32]. However, the use of graduated colors along these shades in the BAR illustration was perceived to be confusing by respondents as evidenced by $44 \%$ of participants stating BAR depicted $21 \%$ risk of fracture as a moderate risk rather than as a high risk of fracture. While a color gradation was used in a prior study, there was no mention of their participants' opinions of color gradation [32]. We conclude that, because the color graduated from orange to red slightly above the $20 \%$ line, participants still considered $21 \%$ to be moderate risk. Our stoplight coloring may limit a color-blind patient's understanding of the depictions. While we used the color system to draw attention and aid in comprehension, we also provided labels to the categories so a color-blind individual could comprehend their risk level. Given the low prevalence of this disorder, specifically in women [40] who represent $80 \%$ of patients undergoing DXA, we feel that using this coloring system would be mostly beneficial.

Our study is not without limitations. Instead of running four separate experiments, we opted to test depictions sequentially in random order. Exposing all subjects to all illustrations may have primed them with greater reinforcement of the information when answering the questions for later illustrations; however we moderated this potential effect by randomizing the order in which illustrations were tested. Similarly, we tested three depictions that were somewhat different from one another and one (FACES) that was different from the others, rather than four similar illustrations. This purposeful variation was a methodologic approach to evaluate which depiction is preferred and led subjects to identify clinically correct risk level comprehension. For example, an icon array such as FACES can help patients visualize their true probability of fracture, but it does not aid them in understanding what is clinically considered high risk. This was evidenced by $75 \%$ of participants who considered a $21 \%$ as a low risk of fracture when viewing FACES. Our study sample was drawn from a general clinic population, which included by chance, some people who had knowledge of OP but others who had 
no prior knowledge of OP. Because some patients may have more knowledge of OP than others, we do not necessarily know if our results might differ between these two subgroups had samples been recruited specifically along these lines. However, for the purposes of PAADRN, this is not necessarily a limitation as we will be recruiting a similar mix of patients. For the purposes of the PAADRN study we wanted to learn which array was preferred and understood by the majority of participants in our target audience, patients undergoing DXA either for the first time or a repeat DXA and who are 50 years of age and older [30]. We found that non-Whites preferred FACES to other illustrations but this was not statistically significant. A larger sample of respondents with lower educational attainment and numeracy may have different responses. Additionally, we used a convenience sampling method which makes it difficult to ascertain that our quantitative results are reflective of the clinic population. However, we did use a more purposeful sampling technique to ensure that our sample was geographically, racially, and economically diverse. One illustration clearly emerged as the most preferred and most easily understood risk depiction among our target audience; however we concur with other researchers that a single risk illustration might not be unanimously accepted by all people [32].

To our knowledge, this is the first study to examine patient preference for communicating FRAX ${ }^{\curvearrowleft}$. We found that numeracy was not significantly associated with preference, perceived ease of understanding, or correct identification of risk category for any of the illustrations examined in this study. Participants were asked to both rate their preferred format and to explain their reason for doing so, and this type of integration of qualitative and quantitative measures moves our understanding or risk communication forward. While participant preference was important in creating the depiction used for the PAADRN trial, we felt it was most important to use an illustration that patients both liked and which was associated with correct appraisal of fracture risk. Additionally, our goal in creating this depiction was not to recommend treatment but rather to choose a depiction that might motivate patients to communicate with their health care provider about their fracture risk or to make health behavior changes like increasing weightbearing exercise or dietary calcium. The PAADRN trial will assess patient motivation and behaviors to improve their bone health upon receiving their illustration of personal fracture risk [30]. We found that the majority of participants in our sample significantly preferred and understood a bar-type graph to display 10-year fracture risk. This illustration could easily be added to DXA reports to aid health care providers and patients in making bone health care decisions. This type of work provides valuable and needed information to health care providers who want to improve DXA follow- up care by using illustrations to communicate personalized fracture risk using a depiction that is well perceived by a general audience of $50+$ years.

\section{Conclusions}

This study describes the methods used to develop a visual depiction of fracture risk that will be mailed with DXA results to patients in the intervention arm of the randomized clinical PAADRN trial. We found that participants had a significant preference for a vertically oriented risk depiction that provided clinically significant risk categories using a stoplight coloring system. As highlighted above, numeracy is an important consideration when communicating risk information to patients. Providing patients with a visual depiction of their personal risk of a disease or disease consequence may assist them in their understanding. However, careful thought should be taken when describing risk to patients, as many adults have low numeracy skills. When determining the best representation of risk obtaining feedback for preference and comprehension from a sample of patients in a target patient population is a critical first step in providing patients with an effective and acceptable risk depiction.

\section{Abbreviations}

OP: Osteoporosis; BMD: Bone mineral density; DXA: Dual energy X-ray absorptiometry; HBM: Health belief model; PAADRN: Patient Activation After DXA Result Notification.

\section{Competing interests}

The authors declare that they have no competing interests with publication of this manuscript. KS has consulted for and received grants from Amgen, Eli Lilly, Novartis, and Merck.

\section{Authors' contributions}

SE conceived of the study, led in its design and coordination, and was one of the lead authors of the manuscript. PC conceived of the study, oversaw and contributed in its design, and assisted in drafting the manuscript. XL assisted in the design of the study, led statistical analysis and assisted in drafting the manuscript. DR assisted in the design of the study, oversaw data collection, and assisted in drafting the manuscript. NW assisted in drafting the manuscript. KS assisted in the design of the study and assisted in drafting the manuscript. SS conceived of the study, led in its design and coordination, and was one of the lead authors of the manuscript. All authors read and approved the final manuscript.

\section{Acknowledgements}

The authors would like to thank Shelly Campo and Natoshia Askelson for their expert advice on the design of the illustrations. We would also like to thank Brandi Robinson, Mollie Giller, Rebecca Burmeister, Roslin Nelson, and Akeba Mitchell for their assistance in data collection and coding. This study is a pilot trial as part of the PAADRN Study registered at clinicaltrials.gov identifier NCT01507662. Dr. Cram is supported by a K24 award from the National Institute of Arthritis and Musculoskeletal and Skin Diseases (AR062133). This work is also funded by R01 AG033035 from the National Institute on Aging at the US National Institutes of Health. The US

Department of Health and Human Services, National Institutes of Health's National Institute on Aging had no role in the analysis or interpretation of data or the decision to report these data in a peer-reviewed journal. Dr. Solimeo received partial support from the Department of Veterans Affairs, Center for Comprehensive Access \& Delivery Research and Evaluation, lowa City VA Health 
Care System, lowa City, IA. The views expressed in this article are those of the authors and do not necessarily represent the views of the

Department of Veterans Affairs or the United States Government.

Preliminary results of this study were presented by:

SW Edmonds, SL Solimeo, X Lu, DW Roblin, KG Saag, P Cram and the PAADRN Investigators in their poster entitled "Optimizing Communication of DXA Results and Fracture Risk to Patients: A Mixed methods Study" at the American Society for Bone and Mineral Research Annual Meeting, 16-20 September 2011, San Diego, CA.

\section{Author details}

'Division of General Medicine, University of lowa Carver College of Medicine, lowa City, IA, USA. ${ }^{2}$ College of Nursing, University of lowa, lowa City, IA, USA. ${ }^{3}$ Faculty of Medicine, University of Toronto, Toronto, ON, Canada. ${ }^{4}$ University Health Network and Mount Sinai Hospital, Toronto, ON, Canada. ${ }^{5}$ Kaiser Permanente Georgia, Atlanta, GA, USA. ${ }^{6}$ School of Public Health, Georgia State University, Atlanta, GA, USA. ${ }^{7}$ Department of Epidemiology, University of Alabama at Birmingham, Birmingham, AL, USA. ${ }^{8}$ Division of Clinical Immunology and Rheumatology, University of Alabama at Birmingham, Birmingham, AL, USA. ${ }^{9}$ Department of Veterans Affairs, Center for Comprehensive Access \& Delivery Research and Evaluation (CADRE), lowa City Veterans Affairs Health Care System, lowa City, IA, USA.

Received: 11 July 2013 Accepted: 29 October 2014

Published online: 25 November 2014

\section{References}

1. NIH Consensus Development Panel on Osteoporosis Prevention, Diagnosis, and Therapy: Osteoporosis prevention, diagnosis, and therapy. JAMA 2001, 285(6):785-795.

2. Kanis JA, Oden A, Johnell O, Johansson H, De Laet C, Brown J, Burckhardt P, Cooper C, Christiansen C, Cummings S, Eisman JA, Fujiwara S, Gluer C, Goltzman D, Hans D, Krieg MA, La Croix A, McCloskey E, Mellstrom D, Melton L, Pols H 3rd, Reeve J, Sanders K, Schott AM, Silman A, Torgerson D, Van Staa T, Watts NB, Yoshimura N: The use of clinical risk factors enhances the performance of BMD in the prediction of hip and osteoporotic fractures in men and women. Osteoporos Int 2007, 18(8):1033-1046

3. Cram P, Rosenthal GE, Ohsfeldt R, Wallace RB, Schlechte J, Schiff GD: Failure to recognize and act on abnormal test results: the case of screening bone densitometry. Jt Comm J Qual Patient Saf 2005, 31(2):90-97.

4. Fitt NS, Mitchell SL, Cranney A, Gulenchyn K, Huang M, Tugwell P: Influence of bone densitometry results on the treatment of osteoporosis. CMAJ 2001, 164(6):777-781.

5. Solomon DH, Morris C, Cheng H, Cabral D, Katz JN, Finkelstein JS, Avorn J: Medication use patterns for osteoporosis: an assessment of guidelines, treatment rates, and quality improvement interventions. Mayo Clinic proceedings Mayo Clinic 2005, 80(2):194-202.

6. Pressman A, Forsyth B, Ettinger B, Tosteson AN: Initiation of osteoporosis treatment after bone mineral density testing. Osteoporos Int 2001, 12(5):337-342

7. Siris ES, Gehlbach S, Adachi JD, Boonen S, Chapurlat RD, Compston JE, Cooper C, Delmas P, Diez-Perez A, Hooven FH, Lacroix AZ, Netelenbos JC, Pfeilschifter, Rossini M, Roux C, Saag KG, Sambrook P, Silverman S, Watts NB, Wyman $A$, Greenspan SL: Failure to perceive increased risk of fracture in women 55 years and older: the Global Longitudinal Study of Osteoporosis in Women (GLOW). Osteoporos Int 2011, 22(1):27-35.

8. Rosenstock IM, Strecher VJ, Becker MH: Social learning theory and the health belief model. Health Educ Q 1988, 15(2):175-183.

9. Cadarette SM, Beaton DE, Gignac MA, Jaglal SB, Dickson L, Hawker GA: Minimal error in self-report of having had DXA, but self-report of its results was poor. J Clin Epidemiol 2007, 60(12):1306-1311.

10. Pickney CS, Arnason JA: Correlation between patient recall of bone densitometry results and subsequent treatment adherence. Osteoporos Int 2005, 16(9):1156-1160.

11. Giangregorio L, Papaioannou A, Thabane L, DeBeer J, Cranney A, Dolovich $L$, Adili A, Adachi JD: Do patients perceive a link between a fragility fracture and osteoporosis? BMC Musculoskelet Disord 2008, 9:38.

12. Doheny MO, Sedlak CA, Estok PJ, Zeller R: Osteoporosis knowledge, health beliefs, and DXA T-scores in men and women 50 years of age and older. Orthop Nurs 2007, 26(4):243-250.
13. Cadarette SM, Gignac MA, Beaton DE, Jaglal SB, Hawker GA: Psychometric properties of the "Osteoporosis and You" questionnaire: osteoporosis knowledge deficits among older community-dwelling women. Osteoporos Int 2007, 18(7):981-989.

14. Nayak S, Roberts MS, Chang CC, Greenspan SL: Health beliefs about osteoporosis and osteoporosis screening in older women and men. Health Educ J 2010, 69(3):267-276.

15. Giangregorio L, Dolovich L, Cranney A, Adili A, Debeer J, Papaioannou A, Thabane L, Adachi JD: Osteoporosis risk perceptions among patients who have sustained a fragility fracture. Patient Educ Couns 2009, 74(2):213-220.

16. Meadows LM, Mrkonjic LA, Lagendyk LE, Petersen KM: After the fall: women's views of fractures in relation to bone health at midlife. Women Health 2004, 39(2):47-62.

17. McLeod KM, McCann SE, Horvath PJ, Wactawski-Wende J: Predictors of change in calcium intake in postmenopausal women after osteoporosis screening. J Nutr 2007, 137(8):1968-1973.

18. Lipkus IM, Samsa G, Rimer BK: General performance on a numeracy scale among highly educated samples. Med Decis Making 2001, 21(1):37-44.

19. Schapira MM, Fletcher KE, Gilligan MA, King TK, Laud PW, Matthews BA, Neuner JM, Hayes E: A framework for health numeracy: how patients use quantitative skills in health care. J Health Commun 2008, 13(5):501-517.

20. White S: Assessing the Nation's Health Literacy: Key concepts and findings of the National Assessment of Adult Literacy (NAAL). Chicago, IL: American Medical Association Foundationln; 2008.

21. Kirsch IS, Jungeblut A, Jenkins L, Kolstad A, Adult Literacy in America: A First Look at the Results of the National Adult Literacy Survey. In vol. NCES 93275. Washington, DC: U.S. Department of Education; 1993.

22. National Osteoporosis Foundation: Clinician's Guide to Prevention and Treatment of Osteoporosis. Washington, DC: National Osteoporosis Foundation; 2008.

23. Goodyear-Smith F, Arroll B, Chan L, Jackson R, Wells S, Kenealy T: Patients prefer pictures to numbers to express cardiovascular benefit from treatment. Ann Fam Med 2008, 6(3):213-217.

24. Hill S, Spink J, Cadilhac D, Edwards A, Kaufman C, Rogers S, Ryan R, Tonkin $A$ : Absolute risk representation in cardiovascular disease prevention: comprehension and preferences of health care consumers and general practitioners involved in a focus group study. BMC Public Health 2010, 10(Journal Article):108.

25. Schapira MM, Nattinger AB, MCAuliffe TL: The influence of graphic format on breast cancer risk communication. J Health Commun 2006, 11(6):569-582.

26. Ghosh K, Crawford BJ, Pruthi S, Williams Cl, Neal L, Sandhu NP, Johnson RE, Wahner-Roedler D, Britain MK, Cha SS, Ghosh A: Frequency format diagram and probability chart for breast cancer risk communication: a prospective, randomized trial. BMC Womens Health 2008, 8(Journal Article):18.

27. Lipkus IM: Numeric, verbal, and visual formats of conveying health risk: suggested best practices and future recommendations. Med Decis Making 2007, 27(5):696-713.

28. Waldron CA, Gallacher J, van der Weijden T, Newcombe R, Elwyn G: The effect of different cardiovascular risk presentation formats on intentions, understanding and emotional affect: a randomised controlled trial using a web-based risk formatter (protocol). BMC Med Inform Decis Mak 2010, 10(Journal Article):41.

29. Montori VM, Shah ND, Pencille $L$, Branda ME, Van Houten HK, Swiglo BA, Kesman RL, Tulledge-Scheitel SM, Jaeger TM, Johnson RE, Bartel GA, Melton $\sqcup$ 3rd, Wermers RA: Use of a decision aid to improve treatment decisions in osteoporosis: the osteoporosis choice randomized trial. Am J Med 2011, 124(6):549-556.

30. Edmonds SW, Wolinsky FD, Christensen AJ, Lu X, Jones MP, Roblin DW, Saag KG, Cram P, The PAADRN Study: A design for a randomized controlled practical clinical trial to improve bone health. Contemp Clin Trials 2013, 34(1):90-100.

31. Dawson-Hughes B, Tosteson AN, Melton $L$ 3rd, Baim S, Favus MJ, Khosla S, Lindsay RL, National Osteoporosis Foundation Guide Committee: Implications of absolute fracture risk assessment for osteoporosis practice guidelines in the USA. Osteoporos Int 2008, 19(4):449-458.

32. Price HC, Dudley C, Barrow B, Kennedy I, Griffin SJ, Holman RR: Use of focus groups to develop methods to communicate cardiovascular disease risk and potential for risk reduction to people with type 2 diabetes. Fam Pract 2009, 26(5):351-358.

33. Fagerlin A, Zikmund-Fisher B, Ubel P, Jankovic A, Derry H, Smith D: Measuring numeracy without a math test: development of the subjective numeracy scale. Med Decis Making 2007, 27(5):672-680. 
34. Chew LD, Bradley KA, Boyko EJ: Brief questions to identify patients with inadequate health literacy. Fam Med 2004, 36(8):588-594.

35. Creswell JW, Plano Clark VL: Designing and Conducting Mixed Methods Research. 2nd edition. Los Angeles, CA: SAGE; 2011.

36. McCaffery KJ, Dixon A, Hayen A, Jansen J, Smith S, Simpson JM: The influence of graphic display format on the interpretations of quantitative risk information among adults with lower education and literacy: a randomized experimental study. Med Decis Making 2012, 32(4):532-544.

37. Feldman-Stewart D, Brundage MD, Zotov V: Further insight into the perception of quantitative information: judgments of gist in treatment decisions. Med Decis Making 2007, 27(1):34-43.

38. Hawley ST, Zikmund-Fisher B, Ubel P, Jancovic A, Lucas T, Fagerlin A: The impact of the format of graphical presentation on health-related knowledge and treatment choices. Patient Educ Couns 2008, 73(3):448-455.

39. Ancker JS, Senathirajah Y, Kukafka R, Starren JB: Design features of graphs in health risk communication: a systematic review. J Am Med Inform Assoc 2006, 13(6):608-618

40. Xie JZ, Tarczy-Hornoch K, Lin J, Cotter SA, Torres M, Varma R: Color vision deficiency in preschool children: the multi-ethnic pediatric eye disease study. Ophthalmology 2014, 121(7):1469-1474.

doi:10.1186/s12911-014-0101-y

Cite this article as: Edmonds et al:: Improving bone mineral density reporting to patients with an illustration of personal fracture risk. BMC Medical Informatics and Decision Making 2014 14:101.

\section{Submit your next manuscript to BioMed Central and take full advantage of:}

- Convenient online submission

- Thorough peer review

- No space constraints or color figure charges

- Immediate publication on acceptance

- Inclusion in PubMed, CAS, Scopus and Google Scholar

- Research which is freely available for redistribution 